\title{
PREVALENCE OF Listeria IN FRUITS AND VEGETABLES
}

\author{
VAISHNAVI SHET ${ }^{*}$ AND DILECTA D'COSTA \\ Department of Microbiology, Government College of Arts, Science and Commerce, Khandola, \\ Marcela, Pincode-403107. Goa, India \\ *Corresponding Author: Dr. Vaishnavi Shet: E Mail: vaishnavishet37@gmail.com
}

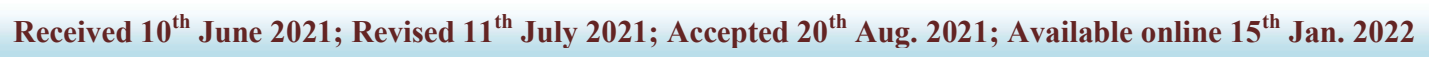

https://doi.org/10.31032/IJBPAS/2022/11.1.1028

\begin{abstract}
Listeria monocytogenes contamination in fruits and vegetables has become an increasing cause for concern in recent years. Fruits and vegetables are considered to be a source of high nutrient value as a result of which their consumption as raw natural food in the form of salads and RTE food has been increasing. However, Listeria monocytogenes, a food-borne pathogen associated with them, has been known to cause serious listeriosis infection, with symptoms of varying severity such as fever, headache, tiredness, gastroenteritis, septicaemia, meningitis and even lead to abortion or stillbirth in pregnant women. This review article aims to provide collective data on the prevalence of Listeria spp. in fruits and vegetables. It also discusses different sources of contamination of fruits and vegetables and pathogenesis of L. monocytogenes leading to listeriosis infection in humans. Listeria monocytogenes has ability to cross different host barriers like placental, intestinal and blood-brain barrier. Being a psychrotrophic microorganism, Listeria grows and survives at low temperatures. Therefore, presence of L. monocytogenes may pose risk of food borne illnesses from consumption of raw or minimally processed fruits and vegetables. This review also provides an inventory of the current data on Listeria monocytogenes causing listeriosis outbreaks, some of them leading to major recalls of the produce. It is virtually impossible to get rid of Listeria monocytogenes from food environment because of its ubiquitous presence. Hence, there is a need to actively manage the elimination and exclusion of this organism.
\end{abstract}

Keywords: Listeria monocytogenes, Listeriosis outbreaks, Pathogenesis of Listeria monocytogenes, Prevalence in fruits and vegetables 


\section{INTRODUCTION}

Listeriosis is a serious illness caused by Listeria and it can be very dangerous for those people at risk. Listeria bacteria are found widely in nature. Eating food contaminated by certain types of Listeria bacteria can cause listeriosis. Fruits and vegetables, cold meats, cold cooked chicken, chilled sea food, cheese, ice cream and other dairy products are some examples of food which are at higher risk of Listeria contamination. The bacteria may be present in raw foods or may even contaminate food after it has been cooked or processed. Storing contaminated foods, also in refrigerator, may allow the Listeria bacteria to grow.

Older people (over 65-70 years), pregnant women, their unborn and newborn children, immune compromised people due to serious illnesses like cancer, leukaemia, AIDS, diabetes, kidney or liver disease, including organ transplant patients are at higher risk of listeriosis.

Symptoms in people at risk may include headache, fever, tiredness, aches and pains. Less common symptoms are nausea, diarrhoea and abdominal cramps. These symptoms may progress to more serious forms of illness, such as septicaemia and meningitis. In pregnant women, symptoms may be mild, but listeriosis can result in miscarriage, premature birth or in rare cases, stillbirth. Blood, Cerebral Spinal Fluids, spleen and liver, which are the sterile parts of the body, are usually infected by Listeria monocytogenes.

The number of cases of listeriosis in humans has increased in the last years due to consumption of fresh fruits and vegetables. Listeria monocytogenes is one of the serious food borne pathogens associated with fruits and vegetables, causing human listeriosis.

For a healthy diet, fruits and vegetables became an important component. Fresh produce provide a variety of nutrients (vitamins, carbohydrates and proteins) and numerous health related benefits to human body due to the phytochemicals with healthy properties, thus increasing the consumption of vegetables is a policy common to several countries (Miceli \& Settanni.,2019). Although spoilage bacteria, yeasts and moulds dominate the microflora of fruits and vegetables, pathogenic bacteria, parasites and viruses capable of causing human infections are occasionally present on the fresh produce (Miceli \& Settanni.,2019). The presence of pathogenic bacteria on fresh-cut products that are consumed raw can cause food-borne outbreaks (Miceli \& Settanni.,2019).

The genus Listeria includes 21 species (Orsi \& Wiedmann.,2016), with Listeria grayi, Listeria innocua, Listeria ivanovii, Listeria 
monocytogenes, Listeria seeligri and Listeria weishimeri being those mostly characterised (Rocourt \& Cossart., 1997) and Listeria costaricensis being the species more recently described (Nunez-Montero et al., 2018). (Miceli \& Settanni., 2019)

Listeria monocytogenes occurs ubiquitously in soil, water and manure, which increases the possibility of vegetables and fruits to be contaminated. Listeria monocytogenes bacteria have been isolated from market or restaurant produce such as Cabbage, Corn, Carrots, Lettuce, Cucumbers, Parsley and salad vegetables (Zhu et al., 2017).

Storage of fruits and vegetables at low temperatures in the refrigerator is thought to reduce its spoilage and extend its shelf life. But being a psychrotrophic microorganism, Listeria grows and survives at low temperatures. For mesophilic microorganisms, spoilage can be prevented, when stored at low temperatures, but the presence of psychrotrophic pathogen such as Listeria might pose risk of food borne illness from consumption of raw or minimally processed fruits and vegetables. Technical reports describe that Listeria monocytogenes can grow under a wide range of growth conditions during food processing and storage, for example, at temperatures as low as $-0.4^{\circ} \mathrm{C}$ and over a wide range of $\mathrm{pH}$ values from 4.3 to 9.4
(Zhu et al., 2017).

Growth of Listeria monocytogenes is dependent on surface properties like topography, availability of nutrients, and moisture content. Surfaces of intact fruits and produce are different. Growth of food borne pathogens on intact produce surfaces is less likely to occur compared with cut produce surfaces, owing to the protective outer barriers on most intact produce (Marik et al., 2019) (Han et al., 2000) (Scallan et al., 2011) (Takeuchi et al., 2000) (Tian et al., 2013). Nutrient and availability of moisture may be restricted by outer protective layers of the produce. Once the outer protective epidermal layer has been disrupted, food borne pathogen like Listeria monocytogenes can enter inside and increase its population. Produce that has been injured through peeling, cutting, slicing or shredding can provide microorganisms access to nutrients and water (Marik et al., 2019). The surface topography of fruits and vegetables can be quite complex (Marik et al., 2019). For example, studies have hypothesised that the extensive netting on the rind or surface of cantaloupe increased adherence, biofilm formation and growth of Listeria monocytogenes ( Marik et al.,2019).

Listeria monocytogenes is a matter of concern for growers and packers because it is encountered in the same environment where 
fresh fruits and vegetables are grown. Fresh fruits and vegetables can be easily contaminated with Listeria bacteria from the soil, water and decaying vegetations. It can easily establish itself in common conditions in packaging facilities. These Listeria bacteria can be introduced into packaging facilities through raw fruits and vegetables from the fields and become established if proper sanitation practices are not carried out.

It has been observed that most food borne outbreaks in the world recently are due to contamination of fruits and vegetables with Listeria monocytogenes. In order to break this trend, it has become a food safety challenge now to prevent the contamination of fresh fruits, vegetables and other produce which are associated with outbreaks of Listeriosis.

Contamination of Fruits \& Vegetables By $L$. monocytogenes

Studies have found that, leafy vegetables were easily contaminated with soil and microorganisms, because of their larger surface area, and leafy vegetables were found to harbour more microorganisms than nonleafy vegetables.

Listeria monocytogenes is widely present in soil environment which may influence its presence and levels in fresh produce due to agricultural practices applied in pre-harvest, post-harvest, as well as handling procedures at the harvest and the environmental biotic \& abiotic factors characterizing the cultivation field.

The number of human listeriosis cases is on increase in the last years and the consumption of fresh fruits and vegetables is more frequently associated with these events. Contamination of fruits and vegetables by Listeria monocytogenes can occur anywhere during transportation or right in the farms, in homes, as well as in restaurants. This could happen due to mishandling and poor hygiene practices during processing and preparation of the foods.

Heavy rains may increase the contamination of crops especially a crop growing low to the ground, such as Cantaloupes, where there is contamination of soil. The splash of rains or even wash waters or irrigation water for that matter could splash bacterium onto the edible surface, thus contaminating the product. Locatelli et al, 2013 said that a bacterium such as $L$. monocytogenes is edaphic, and may last upto 84 days in some soils giving the higher possibilities of contamination in low growing produce.

The use of raw or improperly composted manure can contaminate the soil with $L$. monocytogenes. Major products used as composted manure for crops consists of cattle and chicken feces and animal carcasses, which 
can contain food borne pathogens and ultimately contaminate soil, crops and water resources coming in contact with it (Nightingale et al., 2004). The contaminated crop can cause cross contamination or even increase growth of the organism during harvesting period, which may further result in contamination of other produce and equipments.

Listeriosis outbreak in Jensen farms is a perfect example of how cross contamination played a key role in Listeria monocytogenes infection. In 2011, at Jensen Brother farm in Colorado, L. monocytogenes was found on conveyer belts, including shipping and packing equipments. This resulted in the cross contamination of Cantaloupes on the farm. When these Cantaloupes were distributed to a number of states, resulted in listeriosis infection, identified in 28 states (Rothschild., 2011) to affect 146 people and claiming lives of more than 33 people (Bill Marler., 2014). The machinery and equipments had dirt on them since it was impossible to clean them fully. In addition, the potato washing machine was used for washing Cantaloupes which resulted in cross contamination of Cantaloupes. Further, the trucks, including those used to haul rejected Cantaloupes sent to cattle feedlots, were parked next to the packing plant. This made it easy for the trucks to be contaminated with Listeria from the cattle farms (Zhu et al., 2017).

For sprouts, seeds are considered as a main source of contamination. It is not possible to wash off or inactivate pathogens from sprouts completely. The biofilms formed on structures like cotyledons, hypocotyls and roots, protect L. monocytogenes, making it resistant to antimicrobial compounds. (Miceli \& Settanni., 2019)

L. monocytogenes can also be internalised in fruits and vegetables through cuts or puncture wounds, and result in increase in their growth. Studies have reported the internalization of pathogens in plants from soil by root uptake (Franz et al., 2007). The common route of internalization of human pathogens has been proposed to be penetration at cracks in seed coats, invasion at lateral root junctions in seedling, and aerial tissues (Doyle \& Erikson., 2008). (Calix \& Juan., 2019). Food can also get contaminated in the retail environment due to poor hygienic practices. Common sources of contamination of fruits and vegetables by $L$. monocytogenes is shown in Figure 1.

The main control for reducing these risks of contamination are treatment with sanitizers, mostly involving chlorine (Calix \& Juan., 2019). The wash treatments consists of three stages; the first being focused on eliminating debris and organic material, the second stage 
uses a sanitizer in order to reduce cross contamination and reduce microbial load; and third stage uses non-chlorinated water to rinse the product (Allende et al.,2015) (Caleb et al.,2014) (Calix \& Juan.,2019). Pietrysiak et al., 2019 have described various methods to avoid microbial contamination during packing process and decontamination intervention techniques of apples.

According to EcoLab (2015) pathogens such as Listeria can be reduced upto $99.9 \%$ by antimicrobial wash.

Prevention of biofilm formation is an important control measure to reduce the prevalence and survival of L. monocytogenes in growing environments and on fresh produce (Zhu et al., 2017). Overall maintaining good hygiene and sanitation practices can help prevent possible listeriosis infection. Possible control measures that can be taken to prevent food-borne listeriosis infection are shown in

\section{Figure 2.}

Nowadays, one of the technique used for improving crop productivity and quality is Mulching, wherein a protective covering is spread or left on the ground to enrich the soil, prevent evaporation, maintain soil temperature, which changes the biological characteristics of the soil and help in cycling nutrients. Mulching can give cleaner products as it separates the soil from plants, but so far there is no direct evidence of the effect of plastic mulching on $L$. monocytogenes (Miceli \& Settanni.,2019).

\section{Growth Ecology \& Survival Of Listeria monocytogenes}

L. monocytogenes is a Gram positive bacterium that occurs widely in agricultural, aquacultural and food processing environment. A higher prevalence has been found in soils closer to water, soils with higher moisture, soils recently cultivated, irrigated or rained upon, and soils close to pastures. Survival will also vary with soil type and conditions; moist and organic soils permit longer survival than dry, low- organic soils. L. monocytogenes is also a transitory resident of the intestinal tract in humans, with $2-10 \%$ of the general population being carriers of the microorganisms without any apparent health consequences.

The major transmission vehicle for listeriosis is considered to be food. Ready-to-Eat (RTE) foods are of particular significance in listeriosis infections. RTE foods are the ones that are normally eaten raw or that will not be cooked or reheated before serving. This will include fruits and vegetable salads, sandwiches, cooked meats, smoked fish, desserts, and foods that you have cooked in advance to serve cold and eaten without further listericidal steps. Sporadic cases and outbreaks of listeriosis have generally been 
associated with those RTE foods that are held for extended periods at refrigeration or chill temperatures which allow growth to high numbers at the time of consumption (Buchanan et al.,2017).

Many strains of L. monocytogenes are relatively resistant to a number of environmental conditions, such as high salt or acidity in food as well as low humidity or low oxygen in food environments (Buchanan et al.,2017). Although Listeria growth is significantly reduced at low temperatures, the organism has been found to grow and survive at refrigeration temperatures between -0.5 and $9.3^{\circ} \mathrm{C}$ under laboratory conditions (Walker et al.,1990). The ecological and physiological traits of L. monocytogenes allow it to colonize food plant environments, survives hurdles in processing/ storage and proliferate in food products that support growth at low temperatures (Buchanan et al.,2017). The peptidoglycan of bacteria grown at refrigeration temperatures displays typical features of cold adaptation(Lebreton et al.,2016). In addition to an increased abundance of specific surface proteins, the cell wall architecture and chemical modifications of its peptidoglycan backbone are drastically modified, part of which is linked to the activity of cold-shock proteins (Lebreton et al.,2016). Several authors have concluded that it is virtually impossible to permanently eradicate L. monocytogenes from food environments because of its ubiquitous presence in the environment and many potential avenues for entry into the facility. Therefore, elimination and exclusion of the organism must be actively managed, for e.g. by adequate hygiene design of a premise and equipment, effective cleaning and sanitation, personnel and movement of people and materials into areas where food products are exposed. This includes the disassembly of equipment for deep cleaning, among other important control measures for operations producing RTE foods, like to be associated with sporadic illnesses or outbreaks of listeriosis (CAS 2009)(Buchanan et al.,2017).

\section{Pathogenesis of Listeria monocytogenes}

Listeria monocytogenes is a well known foodborne pathogen causing listeriosis and known to infect both animals and humans. It has ability to cross different host barriers like placental barriers, intestinal barriers and bloodbrain barrier.

Listeriosis infection typically starts with ingestion of food contaminated with Listeria monocytogenes. Once it enters intestine, it can invade different epithelial regions of the intestine. Listeria can target either tip of the villi where apoptic cells are extruded or it can cross the intestinal epithelium through Goblet 
cells. Crossing of the intestinal barriers starts by the interaction of the bacterial protein Internalin A with E-cadherin, a human specific receptor (Lebreton et al.,2016). After internalisation of Listeria bacterium, it is further transcytosed to Lamina propria and into the bloodstream. It then spreads to spleen and liver.

During pregnancy, at the syncytiotrophoblast, the bacterium binds to two surface receptors Ecadherin and C-met, via two surface proteins Internalin $\mathrm{A}$ and Internalin $\mathrm{B}$, respectively, allowing crossing of placental barrier and infection of fetus which is otherwise protected. Listeria has the ability to alter host cell physiology before it enters inside, at the level of infecting organs. The bacterium starts this process by secreting the toxin Listeriolysin $\mathrm{O}$ (LLO) (Lebreton et al.,2016). This toxin creates pores in the host membrane, through which ions pass in or out. This disruption in the ion balance promotes bacterial entry inside the cell.

Mitochondria forms a highly active network in the cell, which constantly undergo fission and fusion. But when influenced by $\mathrm{Ca}^{2+}$ ions, fission becomes dominant. Listeria monocytogenes is benefited by this transient fragmentation of mitochondria.

Disruption of the host ion balance by LLO, also indirectly influences processes inside the nucleus (Institut pasteur, Paris, France).

Listeria interferes with histone posttranscriptional modifications and thus alters the expression of host genes which are involved in immune responses.

In addition to histone dephosphorylation, LLO can alter other post-translational modifications such as SUMOylation (a post-translational modification process). UBC9 , a critical enzyme of this pathway is degraded in response to LLO leading to impairment of host SUMOylation and alteration of several host protein activities including transcription factors. By all these processes, the bacterium can modulate cell functions of the host before its entry. (Pascale Cossart Laboratory, Paris, France).

When the bacterium binds to receptors Ecadherin and $\mathrm{C}$-met on the cell membrane, it triggers cytoskeleton rearrangements which leads to internalisation of Listeria into the cytoplasm. The bacterium secretes LLO and Phospholipases once it is inside, to disrupt the cell membrane of the internalisation vacuole. It also becomes resistant to cell's inner defences by modifying its surface. It then grows and multiplies inside its host and trade-off distinct cellular functions by secreting virulence factors such as InlC and LntA.

Inside cells, one of the poles of the Listeria bacterium is covered with Act A, a bacterial 
factor that engages small actin filaments rapidly grow to form comet tails (Lebreton et al.,2016), which helps Listeria to move further. This movement propels the bacterium to the neighbouring cells through cell membrane. The double membrane vacuole formed again is ruptured by the release of LLO toxin and bacterial Phospholipases, thereby spreading the infection further.

In response to bacterial infection, immune cells of the host, like neutrophils can destroy infected cells, hence controlling the spread of infection. L. monocytogenes can be totally eliminated with the help of adaptive immunity, but in immune-compromised individuals, it may lead to severe listeriosis symptoms.

\section{Listeriosis Outbreaks \& Major Recalls}

\section{Associated With It}

Several outbreaks of listeriosis infection associated with fruits and vegetables have been reported in various parts of the world and it has become an increasing cause for concern. It has been also observed that most of these outbreaks are due to contamination of the produce with Listeria monocytogenes. For example, L. monocytogenes was responsible for death of 10 people in a food poisoning listeriosis outbreak in chopped Celery in Texas in 2010; In 2011, 30 people were infected by Listeria-contaminated in Melons in Colorado; and in 2014, a Listeria outbreak linked to
Caramel apple contamination was reported in California (Zhu et al.,2017).

In 1997, a serious Listeria outbreak occurred in two primary schools and a University in Italy, which was associated with canned corn contaminated by L. monocytogenes. Fever and gastroenteritis were the main symptoms in this outbreak. A total of 2930 people developed febrile gastroenteritis in these three institutes, including primary school students aged 6-10 years, adult staff in the primary school, and students at the University. Investigations showed that after eating food supplied by the same caterer, symptoms were shown. Outside these three institutes in the same area, no other cases were reported during 1997. (Zhu et al.,2017)(Aureli et al.,2000)

European Union has seen an increase in notifications of both listeriosis outbreaks and sporadic cases. EFSA reported that in 2013, 1763 confirmed human cases of listeriosis were reported in 27 member states (Buchanan et al., 2017). Implicated food vehicles were Crustaceans, shell fish and molluses and product thereof, cheese, meat and meat products, pig meat and product thereof, and vegetables and juices and product thereof (mixed salad) (Buchanan et al., 2017).

Since 2010, US has experienced a number of listeriosis outbreaks attributed to foods considered to be "moderate risk" or "low risk" 
by the existing risk assessments, including fruit and vegetables (e.g., Celery, lettuce, cantaloupe, sprouts, stone fruits, and caramel apples), as well as ice creams. (Buchanan et al., 2017).

In 2010, the outbreak that was reported in Texas, was associated with diced, machine cut celery served in five different hospitals (Gaul et al.,2013). There were over 55 patients, with a mean age of 80 , having some or the other health problem. These patients were receiving corticosteroids or acid- reducing treatments, that could have increased their susceptibility to invasive listeriosis (Buchanan et al., 2017). An outbreak of listeriosis was reported in the United States between 2013 and 2015 involving 9 cases, all of whom were hospitalized, with fatalities. Epidemiological and microbiological evidence indicated that the source was frozen vegetables from a single producer in Washington state. Whole genome sequencing (WGS) showed that Listeria monocytogenes from frozen corn was similar to isolates from 8 human cases, and an isolate from peas from the same manufacturer yielded a different L. monocytogenes strain which was similar to that from an additional human case. A further outbreak of listeriosis occurred between 2015 and 2018 and involved 53 cases across 6 European countries. The source of the outbreak was traced to sweet corn grown and frozen in Hungary. The use of WGS identified the outbreak strain (L. monocytogenes, serovar 4b, multilocus sequence type (ST)6) which was detected in multiple frozen foods and surface swabs from the single plant in Hungary where vegetables were processed. The food chain associated with this producer was highly complex and there was an international recall of products from this plant. (Willis et al., 2020)

There was another outbreak in July 2015 to January 2016 due to Listeria monocytegenes contamination in packaged salads. This outbreak was reported to cause 19 illnesses in nine different states leading to hospitalizations of all the cases, with one reported death (Shah., 2019). The outbreak strain of Listeria monocytogenes was traced back to a particular processing facility in Springfield, Ohio. Several brands and varieties of packaged salads were recalled during this outbreak. (Shah., 2019)

A multi-state listeriosis outbreak in US due to eating of contaminated Cantaloupe, in 2011 infected 147 persons. The median patient age was 78 years; most ill people were over 60 , and $99 \%$ of the patients were hospitalized, seven of which was related to pregnancy or newborns. (Buchanan et al., 2017)

Similarly, 5 people became ill due to eating of Mung bean sprouts contaminated with Listeria 
monocytogenes in 2014, all were hospitalized and there were 2 deaths (Buchanan et al., 2017). FDA detected L. monocytogenes in sprouts and irrigation water samples collected during a routine inspection, and follow-up environmental samples also showed the presence of L. monocytogenes (Buchanan et al., 2017).

In July 2014, a packing company in California recalled various stone fruits (Whole peaches, nectarines, plums, and pluots) due to concerns about L. monocytogenes contamination (Buchanan et al., 2017).

Between 2014-2015 , 35 people were affected with Listeria infection, after eating Caramel apples and 34 of them were hospitalised (Buchanan et al., 2017). This outbreak of listeriosis was again reported in US. $L$. monocytogenes was isolated in the caramel apples as well as from apple packing facility by FDA. Subsequent research showed insertion of the stick into the apple may have created a local microenvironment at the applecaramel interface that supports rapid growth, whereas the apple nor caramel alone do not support growth (Glass et al.,2015) (Buchanan et al.,2017).

The number of human listeriosis confirmed cases increased in the last years with 2536, 2242 and 1720 cases registered in the European economic area in 2016, 2014 and
2012 respectively. (EFSA 2017) (Miceli \& Settanni., 2019). The EU countries with the highest number of listeriosis notified in 2016 were Germany, France, Spain, UK, and Italy (Miceli \& Settanni., 2019). However, this diseases has a low incidence in Europe, since only 1437 listeriosis infections were directly acquired in EU countries out of the total 2536 cases registered in the EU in 2016 (Miceli \& Settanni., 2019).

Besides the 2011 contamination of Cantaloupes by the Jensen Brothers in Colorado, there was also 2016 contamination of L. monocytogenes in frozen vegetable blends due the possible contaminated Onions. Those products were produced by the Pictsweet Co., where Onions were from Oregon Potatoes Co. (Alicia Thomas, Master's degree thesis).

In 2015, Granny Smith and Gala Apples were recalled from Bidart Brothers of Bakersfield, $\mathrm{Ca}$, which tested positive for Listeria in the packaging plant. (CDC, 2015). According to the CDC February 2015 Listeria outbreak report, there were a total of 35 cases, 7 deaths and 34 hospitalisations from 12 different states, and one in Canada.

A further case of Listeria meningitis occurred in England in February 2019 and this strain was also recovered from frozen sweet corn and cheese samples. The sweet corn was from one 
of the recalled batches traced to Hungarian plant (Willis et al., 2020). National surveillance of listeriosis in England and Wales reported that, in 2019 there were a total of 142 cases of listeriosis in England and Wales, out of which, 139 were reported in England and 3 cases were reported in Wales. There were 23 deaths reported during this period, out of these, 15 were known to have a clinical manifestation of invasive $L$. monocytogenes infection recorded as a cause of death. Out of the 139 cases reported in the England, 16 were reported in East Midlands, 7 cases were in East of England, 35 cases in London, 6 cases in North East, 19 cases in North West , 10 cases in South West, 18 cases in South East, 12 cases in Yorkshire and the Humber, and 16 cases were reported in West Midlands.

A multi-country outbreak of Listeria monocytogenes ST6 linked to blanched frozen vegetables (bfv) also took place in the EU(2015-2018) (EFSA BIOHAZ Panel et al.,2020). Hygiene of the raw materials, processing water, poor hygienic conditions of the food processing environment and temperature conditions used for storage and processing seem to be the main factors affecting the contamination and growth of $L$. monocytogenes in bfv.

There was a recent recall in June-July 2019 due to possible Listeria monocytogenes contamination in packaged produce, such as butternut squash, cauliflower, zucchini, and a butternut squash based veggie bowl (Shah., 2019). In November 2019, several other recalls have been initiated in various produce types due to possible Listeria

monocytogenes contamination in produce like veggie trays, broccoli, tomatoes, snap peas, veggie power blend, and stir fry blends to name a few, by numerous distributors and retailers. (Shah., 2019)

It is important to note that hospitalization and death rates are higher for patients with Listeriosis infection. This is because of the greater mortality rate due to Listeria monocytogenes, which is as high as $30 \%$ (Scallan et al., 2011). A detailed summery of listeriosis outbreaks from the year 1979 to present due to eating of fruits and vegetables contaminated with L. monocytogenes is given in Table 1. 


\begin{tabular}{|c|c|c|c|c|c|}
\hline \multicolumn{6}{|c|}{ TABLE 1: Food-borne outbreaks caused by $L$. monocytogenes in fruits \& vegetables from 1979 to present } \\
\hline Year & Product & Country & No. of cases & No. of deaths & Reference \\
\hline 1979 & $\begin{array}{c}\text { Raw vegetables (Tomato, } \\
\text { celery, lettuce) }\end{array}$ & United States & 20 & 5 & Ho et al., 1986 \\
\hline 1981 & Coleslaw & Canada & 41 & 17 & Schlech et al., 1983 \\
\hline 1997 & Corn & Italy & 1566 & $\mathbf{0}$ & Aureli et al., 2000 \\
\hline 2008 & Alfalfa sprouts & United States & 20 & $\mathbf{0}$ & Marik et al., 2020 \\
\hline 2010 & Rockmelon & Australia & 9 & 2 & Popovic et al., 2014 \\
\hline 2010 & Chopped celery & United States & $\mathbf{1 0}$ & 5 & Gaul et al., 2012 \\
\hline 2011 & Cantaloupe, Melon & United States & 147 & 33 & Marik et al., 2020 \\
\hline 2011 & Romaine lettuce & United States & 99 & 15 & Miceli \& Settanni, 2019 \\
\hline 2013 & Vegetables & Germany & 3 & 1 & Ricci et al., 2018 \\
\hline 2014 & Stone fruit & United States & 4 & 1 & Jackson et al., 2015 \\
\hline 2014 & RTE salad & Switzerland & 32 & 4 & Stephan et al., 2015 \\
\hline 2014 & Mung bean sprouts & United States & 5 & 2 & Marik et al., 2020 \\
\hline 2015 & Caramel apples & $\begin{array}{c}\text { Canada \& United } \\
\text { States }\end{array}$ & 35 & 7 & Marik et al., 2020 \\
\hline 2016 & Frozen vegetable products & United States & 9 & 3 & Marik et al., 2020 \\
\hline 2016 & Packaged salads & $\begin{array}{c}\text { Canada \& United } \\
\text { States }\end{array}$ & 33 & 4 & Marik et al., 2020 \\
\hline 2018 & Rockmelon & Australia & 19 & 8 & Marik et al., 2020 \\
\hline 2019 & Frozen sweet corn & England & 139 & 23 & $\begin{array}{c}\text { National surveillance } \\
\text { report of listeriosis in } \\
\text { England }\end{array}$ \\
\hline
\end{tabular}

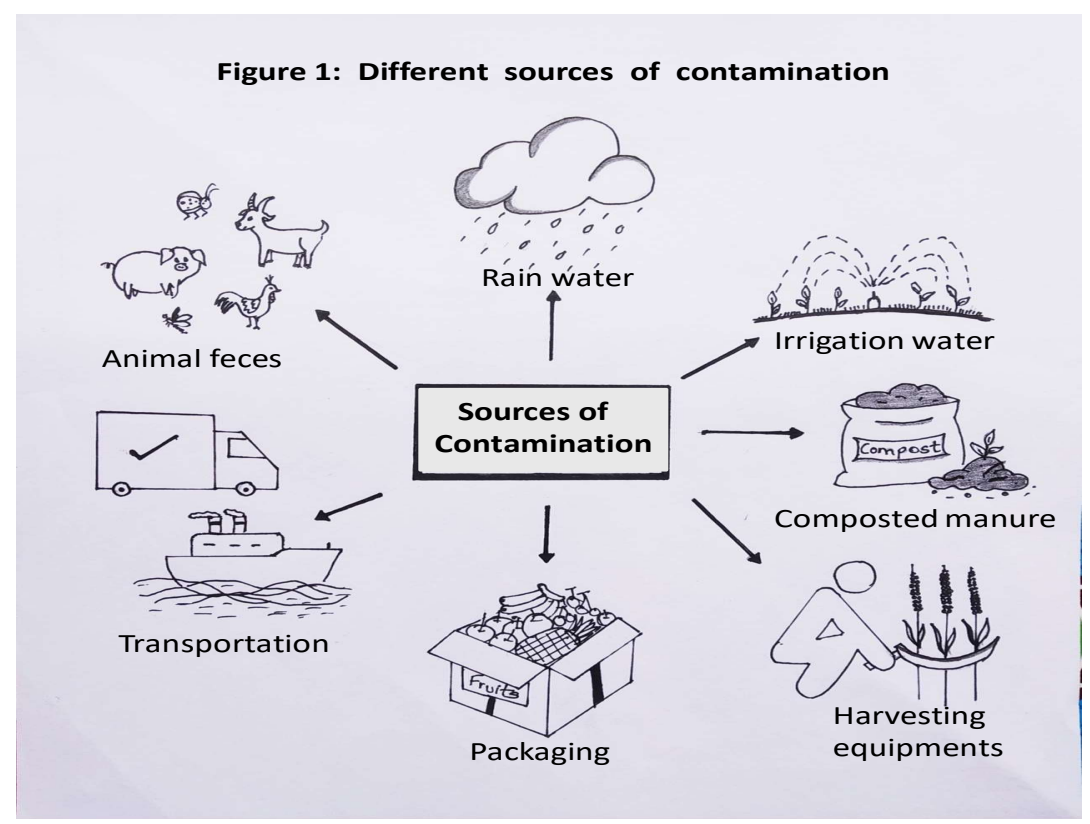


Figure 2: Control measures to prevent food-borne Listeriosis

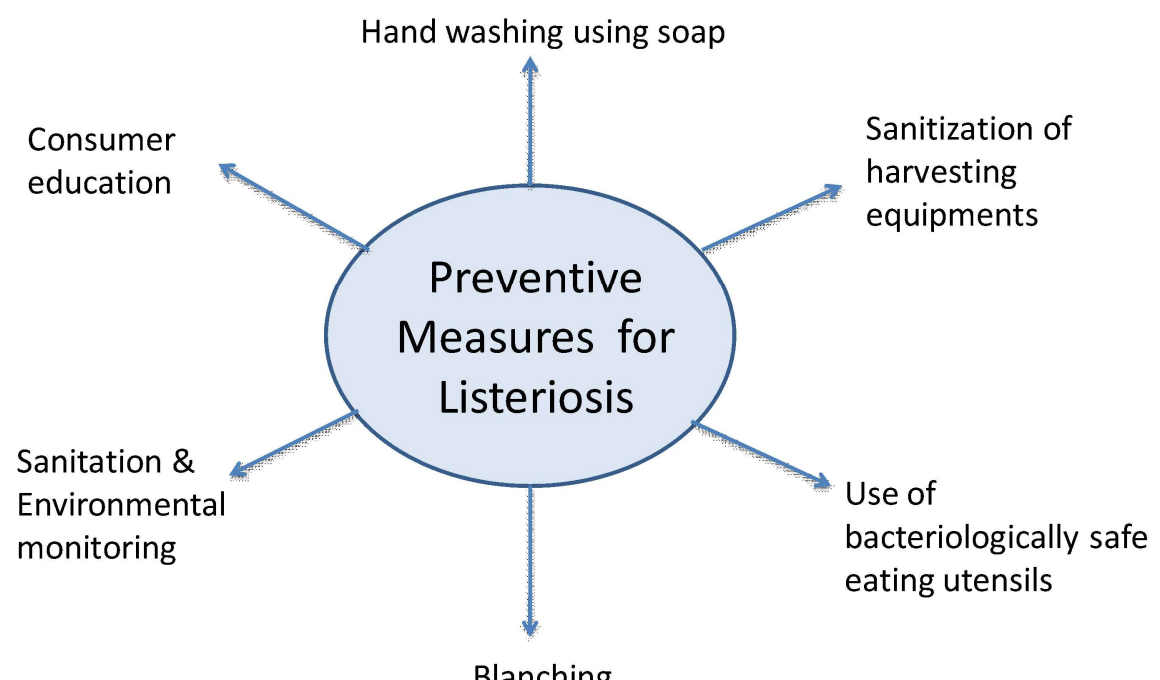

Blanching

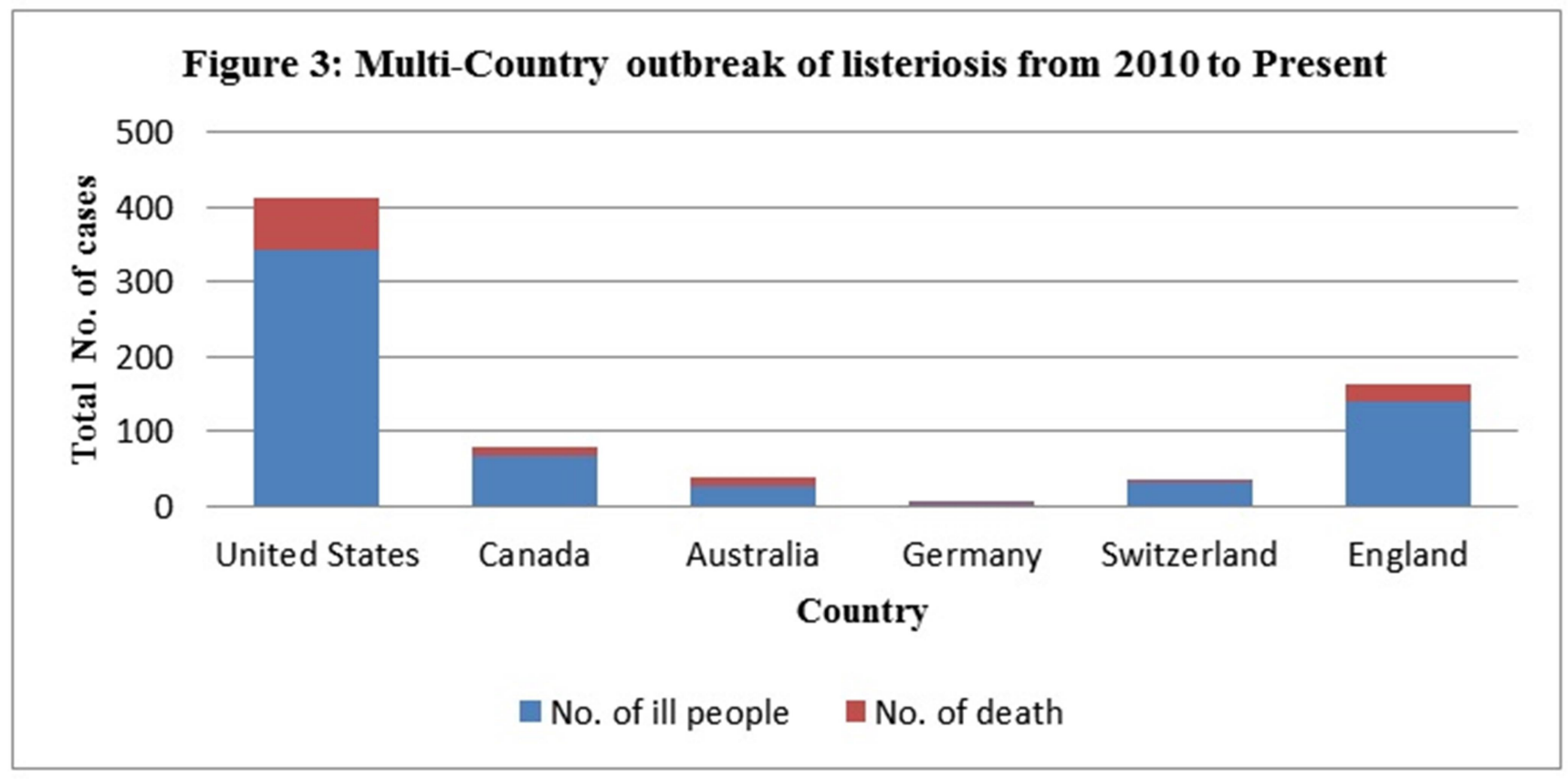




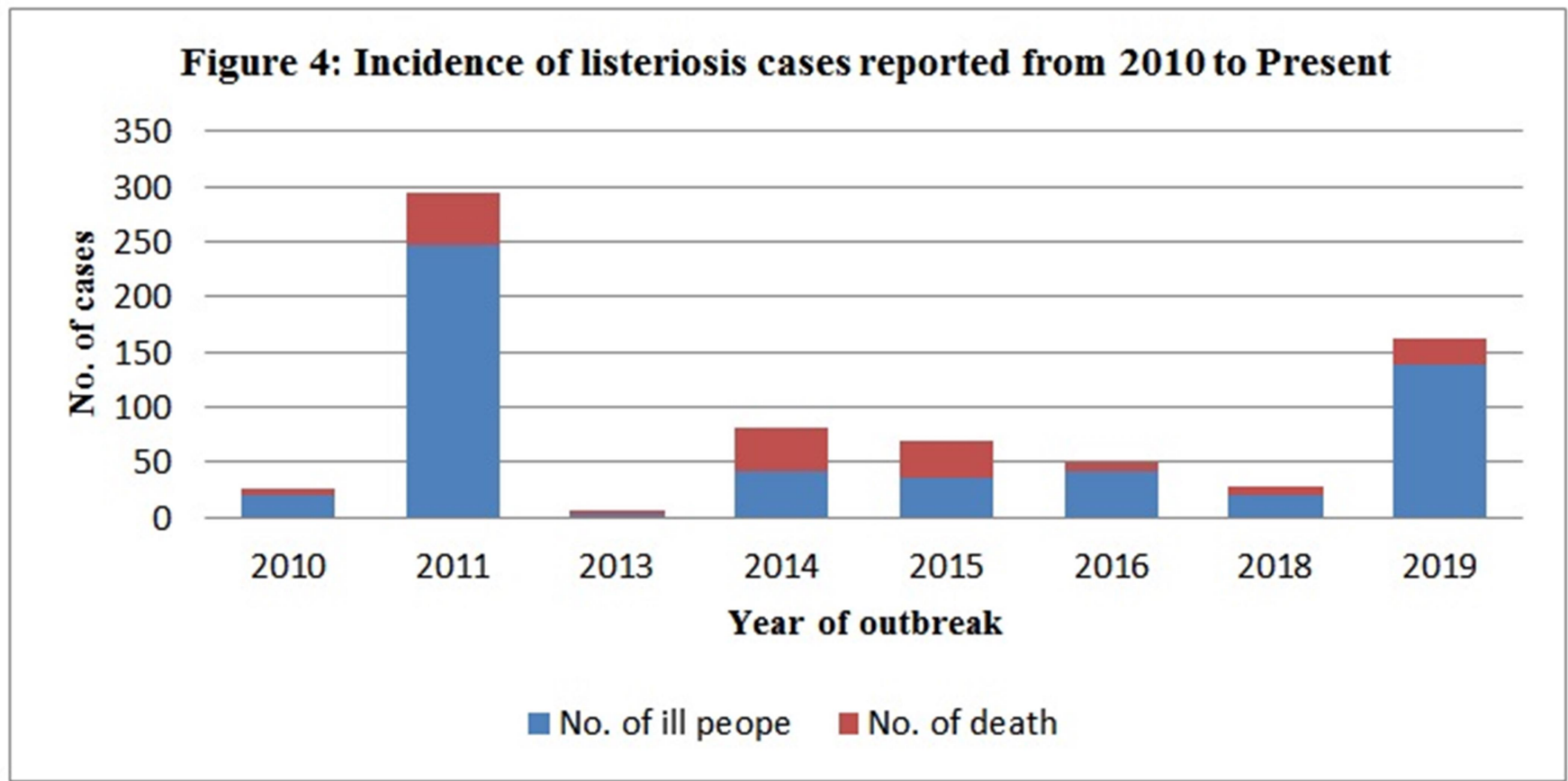

\section{DISCUSSION}

In recent years, Listeria monocytogenes has caught attention for causing several outbreaks related to different fruits and vegetables across the world. Since L. monocytogenes occurs ubiquitously in soil, water and composted manure, this increases its possibility of contaminating fruits and vegetables. Many studies have shown the presence of $L$. monocytogenes on fruits and vegetables sourced from its cultivation farms. Zhu and Hussain in 2014 , conducted a study for investigating prevalence of Listeria spp. in four different vegetables commonly used as salads, sampled from two fruit and vegetable markets in Canterbury region of New Zealand. All the samples were tested positive for Listeria in this study. They successfully concluded that ,
Listeria spp. have been frequently detected in market produce such as Cabbage, corn, lettuce, sprouts, cucumbers, potatoes, parsley and watercress. In a study conducted by Tang et al, 2017 in Terengganu, found Listeria monocytogenes in $3.8 \%$ and $7.3 \%$ of vegetables sourced from commercial farms and local farms respectively from a total of 327 vegetable samples.

Many other research reports also indicated the presence of Listeria spp., Listeria monocytogenes in particular, on the surface of fruits and vegetables. Althaus et al found that the samples of RTE lettuce were infected by $L$. monocytogenes (Zhu \& Husaain, 2014). In another report, Uzeh and Adepoju showed $L$. monocytogenes was present on salad vegetables (sliced Cabbage, lettuce and carrot) 
(Zhu \& Hussain, 2015) (Uzeh \& Adepoju, 2013). Storage temperature was linked to the growth of L. monocytogenes. Chen et al., 2019 also concluded in his study that $5.49 \%$ of fresh vegetables collected from 43 representative cities/ regions markets in China were positive for L. monocytogenes.

Relative humidity is likely an important factor in assessing the likelihood of Listeria monocytogenes growth and/or survival on intact produce and may be a potential control strategy for limiting L. monocytogenes growth and/or survival on intact produce during certain activities for e.g. transportation and storage. (Marik et al.,2019). Usually, for growth of $L$. monocytogenes, the outer surface environment of fruits and vegetables was not favourable, but it was observed that mishandling and storage conditions of these produce, enhanced the survival of L. monocytogenes along the supply chain to the consumers.

Data from Zhu and Hussain, 2014 study and several other study reports strongly suggested that Listeria spp. could pose a serious threat to the safety of fresh fruits and vegetables produce, and products that contain them as a main ingredient. Hence, it is necessary to take appropriate measures to minimize the contamination. Several methods have been developed to control the levels of $L$. monocytogenes on the surface of fresh vegetables and fruits. for e.g., using balsamic vinegar from Moden approved more effective than washing, in reducing pathogens including L. monocytogenes (Zhu \& Hussain, 2014). It is also suggested that dry place with less humidity is more fitful storage condition for fresh produce (Zhu \& Hussain, 2014).

Studies have shown that, highest number of listeriosis outbreaks have occurred in both United states and Europe. Figure 3 shows the total number of listeriosis cases from the year 2010 to present, due to eating of contaminated fruits and vegetables, in six different countries i.e. United States, Canada, Australia, Germany, Switzerland and England. It shows that from the year 2010 to present, United States have had the highest number of listeriosis cases, followed by England (Figure 3). In England, the outbreak was recent, i.e. in 2019, which was due to eating of frozen sweet corn.

Similarly, figure 4 shows the incidence of listeriosis cases reported from the year 2010 to present, due to eating of contaminated fruits and vegetables by Listeria monocytogenes across the world. It shows that, in 2011 the world had highest number of listeriosis cases due to eating of contaminated fruits and vegetables. Listeriosis outbreaks revealed that improper sanitation and cleaning practices of fruits and vegetables, their packing and retail environment may lead to contamination of the 
produce with L. monocytogenes.

Willis et al., 2020 conducted a study to provide data on the microbiological quality and safety of frozen fruits and vegetables in catering premises and on retail sales in England. A total of 1050 samples of fruits and vegetables were collected from various premises by sampling officers from 91 Environmental Health Departments in England between December 2018 and April 2019. Out of these, Listeria monocytogenes was detected in $78(7 \%)$ of the total samples and comparatively, more was detected in vegetables than in fruits.

\section{CONCLUSION}

Fresh fruits and vegetables are considered to be in the top list of healthy foods with lots of nutritional value, that is why all the people, including sick and vulnerable populations are inspirited to eat more of these produce. Having said that, it would be frightening situations to have where L. monocytogenes was routinely isolated from such food sources. Hence in order to implement proper mitigation strategies to reduce their food safety risks, it is important to understand the prevalence of $L$. monocytogenes contamination in fruits and vegetables. In USA, a survey conducted by Luchansky et al., for Listeria monocytogenes prevalence on raw cut vegetables $(1,689)$, low acid cut fruits $(2,408)$, and sprouts $(2,652)$ showed that 18,9 and 3 samples, respectively, for each product type were positive for Listeria monocytogenes (Shah, 2019). Once present on the produce, Listeria monocytogenes can survive for long time periods as this pathogen is adapted to such conditions.

A product recall can ruin manufacturer's reputation and can lead to financial crisis due to loss of large consignments of the produce. Small scale producers may not be able to recover from such recalls. Therefore, it is necessary to monitor and analyze environmental contaminant and health related organism like L. monocytogenes.

It is also very important to make consumers aware of such situations, so that cross contaminations at homes can be prevented. Consumers should discard recalled and food borne disease outbreak associated products with longer shelf life, mainly frozen vegetables/fruits, whenever such information is available.

\section{REFERENCES}

[1] Alicia L. Thomas, "Listeria monocytogenes in fresh fruits and vegetables" - Master's degree in Agriculture and Life Science thesis.

[2] Allende, A., Gil, M., Jacxsens, L., Selma, M., Suslow, T., and Uyttendaele, M.,(2015). "Pre- and post harvest preventive measures and intervention strategies to control microbial food 
safety hazards of leafy green vegetables". Critical Reviews in Food Science and Nutrition, 55, 453-468.

[3] Althaus, D., Hofer, E., Corti, S., Julmi, A., and Stephan, R., (2012). "Bacteriological survey of Ready-to-Eat lettuce, fresh cut fruit and sprouts collected from the Swiss market". J. Food. Protect. 75, 1338-1341.

[4] Aureli, P., Fiorucci, G.C., Caroli, D., Marchiaro, G., Novara, O., and Salmaso, S., (2000). "An outbreak of Febrile gastroenteritis associated with corn contaminated by Listeria monocytogenes". N. Engl. J. Med., 342, 1236-1241.

[5] Buchanan, R., Gorris, L., Hayman, M., Jacson, T., and Whiting, R.,(2017). "A review of Listeria monocytogenes: An update on outbreaks, virulence, doseresponse, ecology, and risk assessments". Food control, 75:1-13.

[6] CAC (Codex Alimentarius Commission), (2009). "Guidelines on the application of general principles of food hygiene to the control of Listeria monocytogenes in foods". CAL/GL 612007.

[7] Caleb, O., Geyer, M., Mahajan, P., Singh, Z., and Watkins, C., (2014). "Postharvest treatments of fresh produce". Philosophical Transactions of the Royal Society, 372, 1-19.

[8] Calix, M., and Juan, F.,(2019). "Effect of storage temperature on the survival or growth of Listeria monocytogenes on whole and fresh cut produce". LSU Master's Thesis. 5026.

[9] CDC, (2015). Multistate Outbreak of Listeriosis linked to commercially produced, Prepackaged caramel apples made from Bidart Bros. apples (Final update).

[10] Chen, M., Chen, Y., Wu, Q., Zhang, J., Cheng, J., Li, F., Zeng, H., Lei, T., Pang, R., Ye, Q., Bai, J., Wang, J., Wei, X., Zhang, Y., and Ding, Y., (2019). "Genetic characteristics and virulence of Listeria monocytogenes isolated from fresh vegetables from China". BMC Microbiology, 19, 119. [11] Doyle, M.P., and Erickson, M.C., (2008). "summer meeting 2007- the problems with fresh produce: an overview". J Appl Microbiol, 105(2), $317-330$

[12] EFSA BIOHAZ Panel (EFSA Panel on Biological Hazards), Koutsoumanis, K., Alvarez-Ordonez, A., Bolton, D., Bover-Cid, S., Chemaly, M., Davies, R., De Cesare, A., Herman, L., Hilbert, F., Lindqvist, R., Nauta, M., Peixe, L., 
Ru, G., Simmons, M., Skandamis, P., Suffredini, E., Jordan, K., Sampers, I., Wagner, M., Da Silva Felicio, M.T., Georgiadis, M., Messens,W., Mosbach-Schulz, O., and Allende, A., (2020). "Scientific Opinion on the public health risk posed by Listeria monocytogenes in frozen fruit and vegetables including herbs, blanched during processing". EFSA Journal, 18(4):6092, 102pp.

[13] Franz, E., Visser, A.A., Van Diepeningen, A.D., Klerks, M.M., Termorshuizen, A.J., and Van Bruggen, A. H., (2007). "Quantification of contamination of lettuce by GFP- expressing Escherichia coli O157:H7 and Salmonella enterica Serovar Typhimurium". Food Microbiol, 24(1), 106-112.

[14] Gaul, L.K., Farag, N.H., Shim, T., Kingsley, M.A., Silk, B.J., and HyytiaTrees, E., (2013). "Hospital- acquired listeriosis outbreak caused by contaminated diced celery-Texas, 2010". Clinical Infectious Diseases, $56,20-26$.

[15] Glass, K.A., Golden, M.C., Wanless, B.J., Bedale, W., and Czuprynski, C., (2015). "Growth of Listeria monocytogenes within a Caramel-

coated apple microenvironment". mBio, 6(5), e01232-15.

[16] Han, Y., Sherman, D.M., Linton, R.H., Nielsen, S.S., and Nelson, P.E., (2000). "The effect of washing and chlorine dioxide gas on survival and attachment of Escherichia coli O157:H7 to green pepper surfaces". Food Microbiol, 17: 521-533.

[17] Ho, L.L., Shands, K.N., Friedland, G., Eckind, P., and Fraser, D.W., (1986). "Sn outbreak of type 4b Listeria monocytogenes infection involving patients from eight Boston Hospitals". Arch. Intern. Med., 146, 520-524.

[18] Jackson, B.R., Salter, M., Tarr, C., Conrad, A., Harvey, E., Steincock, L., Saupe, A., Sorenson. A., Katz, L., Stroika, S., Jackson, K.A., Carleton, H., Kucerova, Z., Melka, D., Strain, E., Parish, M., and Mody, R.K., (2015). "Notes from the field: Listeriosis associated with stone fruitUnited States, 2014". Morb. Mortal. Wkly. Rep., 64, 282-283.

[19] Join-Lambert, O.F., Ezine, S., Le Monnier, A., Jaubert, F., Okabe, M., Berche, P., and Kayal, S.,(2005). "Listeria monocytogenes- infected bone marrow myeloid cells promote 
bacterial invasion of the central nervous system". Cell Microbiol, 7: 167-180.

[20] Lebreton, A., Stavru, R., Brisse, S., and Cossart, P., (2016). "1926-2016: 90 years of listeriology". Microbes and infection, 18, 711-723.

[21] Locatelli, A., Spor, A., Jolivet, C., Piveteau, P., and Hartmann, A., (2013). "Biotic and abiotic soil properties influence survival of Listeria monocytogenes in soil: E75969". Plos One, 8(10).

[22] Marik, C.M., Zuchel, J., Schaffner, D.W., and Strawn, L.K.,(2019). "Growth and survival of Listeria monocytogenes on intact fruit and vegetable surfaces during pot-harvest handling: A Systemic Literature Review". Journal of food protection, 83(1): 108-128.

[23] Miceli, A., and Settanni, L.,(2019). "Influence of agronomic practices and pre-harvest conditions on the attachment and development of Listeria monocytogenes in vegetables". Annals of Microbiology, 69:185-199.

[24] Nightingale, K.K., Schukken, Y.H., Nightingale, C.R., Fortes, E.D., Ho, A.J., Her, Z., Wiedmann, M., (2004). "Ecology and transmission of Listeria monocytogenes infecting ruminants and in the farm environment". Applied and Environmental Microbiology, $70(8), 4458-4467$.

[25] Nunez-Montero, K., Leclercq, A., Moura, A., Vales, G., Peraza, J., Pizarro-Cerda, J. Lecuit, M., (20180. "Listeria costaricensis sp. nov". Int J Syst Evol Microbiol, 68: 844-850.

[26] Orsi, R.H., and Wiedmann, M.,(2016). "Characteristics and distribution of Listeria spp., including Listeria species newly described since 2009". Appl Microbial Biotechnol, 100:5273-5287.

[27] Pietrysiak, E., Smith, S., and Ganjyal, G.M.,(2019). "Food safety interventions to control Listeria monocytogenes in the fresh Apple Packing Industry: A Review". Comprehensive Reviews in Food Science \& Food safety, 18:1705-1726.

[28] Popovic, I., Heron, B., and Covacin, C., (2014). "Listeria: an Australian perspective (2001-2010)". Foodborne pathog. Dis., 11, 425-432.

[29] Ricci, A., Allende, A., Bolton, D., Chemaly, M., Davies, R., Fernandez Escamez, P.S., Girones, R., Herman, L., et al., (2018). "Listeria monocytogenes contamination of 
Ready-to-Eat foods and risk for human health in the EU". EFSA J., 16, 5134.

[30] Rocourt, J., and Cossart, P.,(1997). "Listeria monocytogenes". In: Doyle, M.P., Beuchat, L. R., Montville, T.J., (eds) Food microbiologyfundamentals and frontiers. American Society for microbiology press, Washington, D.C., pp337-352.

[31] Rothschild, Mary, (2011), Listeria outbreak: Cantaloupe contamination. Food safety news.

[32] Scallan, E., Hoekstra, R.M., Angulo, F.J., Tauxe, R.V., Widdowson, M.A., Roy, S.L., Jones, J.L., and Griffin, P.M., (2011). "Foodborne illness acquired in United States-Major pathogens". Emerg. Infect. Dis., 17, 715.

[33] Scallan, E., Hoekstra, R.M., Angulo,F.J., Tauxe, R.V., Widdowsin, M.A., Roy, S.L., Jones, J.L., and Griffin, P.M.,(2011). "Foodborne illness acquired in the United StatesMajor pathogesns". Emerg. Infect. Dis., 17. 7-15.

[34] Schlech, W.F., III, Lavigne, P.M., Bortolussi, R.A., Allen, A.C., Haldane, E.V., Wort, A. J., Hightower, A.W., Johnson, S.E., King, S.H., Nicholls, E.S., and Broome, C.V., (1983).
"Epidemic listeriosis- evidence for transmission by food". N. Engl. J. Med., 308, 203-206.

[35] Settanni, L., and Corsetti, A.,(2007). "The use of Multiplex PCR to detect and differentiate food- and beverageassociated microorganisms: a review". J Microbiol Methods, 69:1-22.

[36] Shah, M., (2019). "Listeria monocytogenes contamination in produce-an increasing cause for concern". FSNS News.

[37] Stephan, R., Althaus, D., Kiefer, S., Lehner, A., Hatz, C., Schmutz, C. Jost, M, Gerber, N., Baumgartner, A., Hachler, H., and Mausezahl-Feuz, M., (2015). "Foodborne transmission of Listeria monocytogenes via Ready-toEat salad: a nationwide outbreak in Switzerland, 2013-2014". Food control, 57, 14-17.

[38] Takeuchi, K., Matute, C.M., Hassan, A.N., and Frank, J.F.,(2000). "Comparison of the attachment of Escherichia coli O157:H7, Listeria monocytogenes, Salmonella typhimurium, and Pseudomonas fluorescens to lettuce leaves". J. Food Prot., 63, 1433-1437.

[39] Tang, J.Y.H., Razali, N.A.S., Jalil, L.A., Mat-Sa'ad, S.H., Nakaguchi, Y., 
Nishibuchi, M., and Radu, S.,(2017).

"Detection of Listeria sp. and Listeria monocytogenes in vegetables by loopmediated isothermal amplification (lamp) and multiplex polymerase chain reaction (pcr)". J. Fundam. Appl. Sci., 9(25), 698-714.

[40] Tian, J.-Q., Bae, Y.-M., and Lee, S.Y., (2013). "Survival of foodborne pathogens at different relative humidities and temperatures and the effect of sanitizers on apples with different surface conditions, Food Microbiol., 35, 21-26.

[41] Uzeh, R.E., and Adepoju, A., (2013). "Incidence and survival of Escherichia coli O157:H7 and Listeria monocytogenes on salad vegetables". Int. Food. Res. J., 20, 1921-1925.

[42] Walker, S.J., Archer, P., and banks, J.G., (1990). "Growth of Listeria monocytogenes at refrigeration temperatures". Journal of applied Bacteriology, 68:157-162.

[43] Willis, C., McLauchlin, J., Aird, H., Amar, C., Barker, C., Dallman, T., Elviss, N., Lai, S., and Sadler-Reeves, L., (2020). "Occurrence of Listeria and Escherichia coli in frozen fruits and vegetables collected from retail and catering premises in England 2018-
2019". International Journal of Food Microbiology, 334.

[44] Zhu, Q., and Hussain, M.A.,(2014). " Prevalence of Listeria species in fresh salad vegetables and Ready-to-Eat foods containing fresh produce marketed in Canterbury, New Zealand". Adv Food Technol Nutr Sci open J, 1(1):5-9.

[45] Zhu, Q., Gooneratne, R., and Hussain, M.A.,(2017). "Listeria monocytogenes in fresh produce: outbreaks, prevalence and contamination levels". foods, 6(3),21.

[46] G. S. Sajja, M. Mustafa, K. Phasinam, K. Kaliyaperumal, R. J. M. Ventayen and T. Kassanuk, "Towards Application of Machine Learning in Classification and Prediction of Heart Disease," 2021 Second International Conference on Electronics and Sustainable Communication Systems (ICESC), 2021， pp. 1664-1669, doi:10.1109/ICESC51422.2021.95329 $\underline{40}$

[47] Veluri, R., Patra, I., Naved, M., Prasad, V., Arcinas, M., Beram, S., \& Raghuvanshi, A. (2021). Learning analytics using deep learning techniques for efficiently managing educational institutes. Materials 
Today: Proceedings.

https://doi.org/10.1016/j.matpr.2021.1

$\underline{1.416}$

[48] C.M. Thakar, S.S. Parkhe, A. Jain et al., 3d Printing: Basic principles and applications, Materials Today:

Proceedings, https://doi.org/10.1016/j.

matpr.2021.06.272 